\title{
Differences in Sucrose Metabolism in Peach Fruit Stored at Chilling Stress versus Nonchilling Stress Temperatures
}

\author{
Fang Yu \\ Department of Food Science and Engineering, Ningbo University, Ningbo \\ 315211, People's Republic of China

\section{Zhiming Ni} \\ Key Laboratory of Healthy \& Intelligent Kitchen System Integration, Ningbo \\ Fotile Kitchenware Co. Ltd, Ningbo 315326, People's Republic of China
}

Xingfeng Shao ${ }^{1}$ and Lina Yu

Department of Food Science and Engineering, Ningbo University, Ningbo 315211, People's Republic of China

Hongxing Liu

Key Laboratory of Healthy \& Intelligent Kitchen System Integration, Ningbo Fotile Kitchenware Co. Ltd, Ningbo 315326, People's Republic of China

Feng Xu and Hongfei Wang

Department of Food Science and Engineering, Ningbo University, Ningbo 315211, People's Republic of China

Additional index words. Prunus persica, sugar metabolism, chilling injury

Abstract. To explore differences in sucrose metabolism between peach fruit subjected to chilling stress $\left(5^{\circ} \mathrm{C}\right)$ and nonchilling stress $\left(10^{\circ} \mathrm{C}\right)$, sucrose concentration as well as the activities and gene expression levels for enzymes associated with sucrose metabolism were compared. Fruits stored at $5{ }^{\circ} \mathrm{C}$ accumulated higher concentrations of $\mathrm{H}_{2} \mathrm{O}_{2}$ and developed severe chilling injury (CI) compared with fruit kept at $10{ }^{\circ} \mathrm{C}$. Activities and gene expression levels for enzymes related to sucrose metabolism, such as acid invertase (AI), neutral invertase (NI), sucrose synthase (SS), and sucrose phosphate synthase (SPS) were higher in fruit stored at $5{ }^{\circ} \mathrm{C}$ than at $10^{\circ} \mathrm{C}$ throughout or late in storage. A sharp increase in net sucrose cleavage activity dramatically decreased sucrose concentration and increased reducing sugars at $5{ }^{\circ} \mathrm{C}$. The sucrose concentration at $10{ }^{\circ} \mathrm{C}$ increased over the first 21 days and then declined slightly, and was higher than in fruit at $5{ }^{\circ} \mathrm{C}$ throughout storage. The increase in net sucrose cleavage activity at $5^{\circ} \mathrm{C}$ is contrary to the expectation that biochemical reactions ordinarily proceed more rapidly with increasing temperature. We conclude that chilling stress stimulates the activities and transcription levels of enzymes involved in sucrose metabolism, resulting in increased sucrose cleavage.

Peaches [Prunus persica (L.) Batsch] are one of the most important fruit crops in the world and are priced because of their rich flavor and nutritional value. Sucrose is the major sugar present, contributing around $75 \%$ of total sugar in the fruit after harvest (Aubert et al., 2014), and the concentration of

Received for publication 20 July 2015. Accepted for publication 2 Sept. 2015.

This study was supported by the Natural Science Foundation of Zhejiang Province (no. LR15C200002), Key Laboratory of Healthy \& Intelligent Kitchen System Integration of Zhejiang Province (no. 2014E10014), the National Science Foundation of China (no. 31000825), the Scientific Research Foundation of Graduate School and the K.C. Wong Magna Fund at Ningbo University.

${ }^{1}$ Corresponding author. E-mail: shaoxingfeng@ nbu.edu.cn. sucrose is directly related to fruit quality and taste (Borsani et al., 2009). Sucrose metabolism is the primary system controlling sugar concentration and composition. Sucrose can be converted to glucose and fructose by $\mathrm{AI}$ and NI, or to fructose by SS cleavage in the presence of uridine diphosphate (UDP). In the reverse reaction, sucrose can be synthesized from glucose and fructose by SS-synthesis or SPS in the presence of UDP-glucose (UDPG). Sucrose also modulates the response in field and model plants to cold (Uemura et al., 2003), heat (Zhao et al., 2013), drought (Hoffmann, 2010), and anoxia (Lara et al., 2011). Sucrose may protect the cytomembrane by acting as a cytoprotectant, scavenge reactive oxygen species (ROS), act as a signaling molecule, and regulate gene expression to protect plants against stress (Wang et al., 2013).
$\mathrm{CI}$ is a physiological disorder accompanying cold stress and is a great concern among peach growers. CI appears within 1 or 2 weeks if fruit is stored at $2-5^{\circ} \mathrm{C}$, or 3 or more weeks at $0{ }^{\circ} \mathrm{C}$ (Lurie and Crisosto, 2005), and is characterized by internal browning, juicelessness, mealiness, internal reddening, and other adverse effects (Crisosto and Labavitch, 2002; Lurie and Crisosto, 2005). CI seriously degrades fruit quality and frequently renders fruit not saleable, resulting in economic loss. Researchers have focused considerable effort on understanding the cause of $\mathrm{CI}$ and identifying potential methods for reducing it. One important contributing factor may be the accumulation of ROS, which destroy membrane systems and induce CI development (Lukatkin et al., 2012). Yang et al. (2011) found that $\gamma$-aminobutyric acid enhanced the activities of antioxidant enzymes such as superoxide dismutase, catalase, and ascorbate peroxidase, and were associated with the increased chilling tolerance in peaches. 1-Methylcyclopropene markedly inhibited $\mathrm{CI}$ incidence in peaches by increasing the activities of antioxidant enzymes and alleviating oxidative damage (Jin et al., 2011). Some reports have called attention to a possible relationship between sucrose and CI in harvested fruit. In mandarin fruit, sucrose rather than glucose, fructose, or starch appeared to be responsible for heatinduced chilling tolerance during cold stress temperature storage (Holland et al., 2002). High sucrose and glucose concentration alleviated CI symptoms in peach fruit (Abidi et al., 2015), and higher concentration of sucrose in 'Yulu' peach fruit may be positively correlated with chilling tolerance (Wang et al., 2013). In other fruit, such as loquat, evidence suggests that reducing sugars, rather than sucrose, are related to CI tolerance (Cao et al., 2013).

Although $5{ }^{\circ} \mathrm{C}$ is commonly used for the storage of fruits and vegetables, it causes severe CI in peach fruit (Lurie and Crisosto, 2005). $0{ }^{\circ} \mathrm{C}$ storage is better than $5{ }^{\circ} \mathrm{C}$ for peaches because CI develops more slowly at this temperature (Lurie and Crisosto, 2005). In contrast, $10{ }^{\circ} \mathrm{C}$ does not cause chilling stress although it is still cold enough for peach storage. In a previous study, we compared soluble carbohydrates in peach fruits stored at 0 and $5{ }^{\circ} \mathrm{C}$ (Wang et al., 2013). However, sugar metabolism in fruit stored at chilling $\left(5^{\circ} \mathrm{C}\right)$ and nonchilling $\left(10^{\circ} \mathrm{C}\right)$ stress temperatures has not yet been compared, and the relationship between sugar and chilling resistance is not understood. In this study, we investigated differences in sucrose metabolism, sucrose concentration, and activities and gene expression levels for related enzymes, in peach fruit subjected to chilling $\left(5^{\circ} \mathrm{C}\right)$ and nonchilling $\left(10^{\circ} \mathrm{C}\right)$ stress for $28 \mathrm{~d}$.

\section{Materials and Methods}

\section{Plant material}

Peaches [P. persica (L.) Batsch cv. Yulu] were hand harvested at commercial maturity 
(135 d after full bloom) from a commercial plantation located in Fenghua, Zhejiang Province, China, and immediately transported to the laboratory.

\section{Treatments}

Fruit were precooled to $10{ }^{\circ} \mathrm{C}$ and manually selected for uniform color, size, and absence of mechanical damage, and then randomly divided into experimental units for either 10 or $5{ }^{\circ} \mathrm{C}$ experiments. For $10{ }^{\circ} \mathrm{C}$ storage, three replicates of 150 fruit were stored at $10{ }^{\circ} \mathrm{C}, 95 \%$ relative humidity $(\mathrm{RH})$ for up to $28 \mathrm{~d}$. For $5{ }^{\circ} \mathrm{C}$ storage, three replicates of 150 fruit were stored at $5{ }^{\circ} \mathrm{C}$, RH $95 \%$ for $28 \mathrm{~d}$. Ten fruit per treatment replicate were sampled after periods of 0,7 , 14,21 , and $28 \mathrm{~d}$ of cold storage. CI indexes were assessed immediately after removal from cold storage, and then slices of mesocarp $(\approx 1 \mathrm{~cm}$ thick) were frozen in liquid nitrogen and stored at $-40{ }^{\circ} \mathrm{C}$ for further use. The entire experiment was conducted twice (in the 2011 and 2013 harvest seasons). The date from the 2013 harvest season was used in here because the same pheromone was used in the two seasons.

\section{Physical and molecular assays}

CI index. CI index was determined using the following scale (Meng et al., 2009), 0: no signs of internal browning; 1: browning area less than $25 \%$; 2 : browning area between $25 \%$ and $50 \% ; 3$ : browning area more than $50 \%$. CI index was calculated as CI index $=$ $\sum[$ (CI scale $) \times$ (number of corresponding fruit at the CI scale)]/(total number of fruit in the treatment group).

$\mathrm{H}_{2} \mathrm{O}_{2}$ concentration. $\mathrm{H}_{2} \mathrm{O}_{2}$ concentration was determined using the method described by Wang et al. (2014). Two grams of flesh tissue were ground with $5 \mathrm{~mL}$ chilled $100 \%$ acetone, followed by centrifugation at 10,000 $g_{\mathrm{n}}$ for $20 \mathrm{~min}$ at $4{ }^{\circ} \mathrm{C}$. The supernatant was collected and assayed for $\mathrm{H}_{2} \mathrm{O}_{2}$ using kits purchased from Nanjing Jiancheng Institute of Bioengineering (Nanjing, Jiangsu, China).

Soluble sugar concentrations. Soluble sugars were measured using the method described by Wang et al. (2013) with modifications. Five grams of fruit flesh were ground with $0.5 \mathrm{~mL}$ of $300 \mathrm{~mm}$ zinc acetate and $0.5 \mathrm{~mL}$ of $63 \mathrm{~mm}$ potassium ferrocyanide. The homogenate was diluted to $25 \mathrm{~mL}$ and passed through $0.22-\mu \mathrm{m}$ membrane filters. A $20-\mu \mathrm{L}$ aliquot was injected into a highperformance liquid chromatography system (model 2695; Waters, New York, NY) fitted with an amino column (Kromasil ${ }^{\circledR} 100 \mathrm{~A}$; Sweden) and a refractive index detector (model 2414; Waters) operating at a flow rate of 1.0 $\mathrm{mL} / \mathrm{min}$ at $35{ }^{\circ} \mathrm{C}$, using acetonitrile/water $(75: 25, \mathrm{v} / \mathrm{v})$ as the mobile phase. Individual sugars were identified and quantified by comparison with the retention times and peak areas of pure sugar standards. The results were expressed as milligrams per gram fresh weight (FW).

Extraction and assay of sucrose metabolismrelated enzyme activities. One gram of frozen mesocarp tissue was homogenized with $5 \mathrm{~mL}$ of $100 \mathrm{~mm}$ sodium phosphate buffer $(\mathrm{pH}=7.5)$ containing $5 \mathrm{~mm} \mathrm{MgCl}_{2}, 1 \mathrm{~mm}$ EDTA, $2.5 \mathrm{~mm}$ DTT, and $0.1 \%(\mathrm{v} / \mathrm{v})$ Triton X-100. The homogenates were centrifuged at $10,000 g_{n}$ for $20 \mathrm{~min}$ at $4{ }^{\circ} \mathrm{C}$, and the supernatants were diluted 1:10 with distilled water before being used for enzyme activity assays.

AI activity was assayed in an incubation mixture of $100 \mathrm{~mm}$ sodium citrate buffer $(\mathrm{pH}=4.5), 1 \%(\mathrm{~m} / \mathrm{v})$ sucrose, and crude enzyme extract. The mixture was incubated at $34{ }^{\circ} \mathrm{C}$ for $30 \mathrm{~min}$, and then the reaction was stopped by boiling for $5 \mathrm{~min}$. NI activity was measured using a similar protocol, except that the incubation mixture was $100 \mathrm{~mm}$ sodium phosphate buffer $(\mathrm{pH}=7.5), 1 \%(\mathrm{~m} / \mathrm{v})$ sucrose, and crude enzyme extract (Shao et al., 2013). Glucose produced by these reactions was measured using the 3,5-dinitrosalicylic acid method (Miller, 1959). AI and NI activities were expressed as micromoles glucose per hour per gram FW.

SS activity consisted of SS-cleavage activity and SS-synthesis activity. For the SS-cleavage activity assay, the reaction, containing $80 \mathrm{~mm}$ Hepes-NaOH $(\mathrm{pH}=5.5), 5 \mathrm{~mm}$ $\mathrm{NaF}, 100 \mathrm{~mm}$ sucrose, $5 \mathrm{~mm}$ UDP and the mixture was incubated at $34{ }^{\circ} \mathrm{C}$ for $30 \mathrm{~min}$, then stopped by boiling for $5 \mathrm{~min}$. The remainder of the assay for SS-cleavage activity was conducted using the same method as for AI.

SS-synthesis and SPS activities were measured according to the method of Solomakhin and Blanke (2010) with modifications. SS-synthesis activity was determined in a reaction mixture of $100 \mathrm{~mm}$ Hepes-NaOH buffer ( $\mathrm{pH}=8.0), 4$ mм UDPG, $60 \mathrm{~mm}$ fructose, $15 \mathrm{~mm} \mathrm{MgCl}_{2}$, and crude extract. The mixture was incubated for $30 \mathrm{~min}$ at $34{ }^{\circ} \mathrm{C}$. The reaction was ended by adding $5 \mathrm{M} \mathrm{NaOH}$ and then placed in boiling water for $10 \mathrm{~min}$. The amount of sucrose formed was determined using the anthrone assay (van Handel, 1968). SPS activity was assayed following the protocol used for SS-synthesis activity but with $5 \mathrm{~mm}$ F6P instead of $60 \mathrm{~mm}$ fructose, $10 \mathrm{~mm}$ UDPG instead of $4 \mathrm{~mm}$ UDPG, and in the presence of $15 \mathrm{~mm}$ G6P. The activities of SS-synthesis and SPS were expressed as micromoles sucrose per hour per gram FW.

The net sucrose cleavage activity was calculated by the formula: the net activity $=$ $(\mathrm{AI}+\mathrm{NI}+\mathrm{SS}-\mathrm{cleavage}$ activities $)-(\mathrm{SS}-$ synthesis + SPS activities)

Quantitative real-time polymerase chain reaction (PCR). Total RNA was extracted from each frozen sample ( $2 \mathrm{~g})$ using the hexadecyl trimethyl ammonium bromide method described by Meisel et al. (2005). Recombinant DNase I (TaKaRa, Japan) was used to remove genomic DNA according to the manufacturer's instructions. RNA sample integrity was examined by electrophoresis on a $2 \%$ agarose gel. Finally, first-strand cDNA synthesis was performed using the PrimeScript RT reagent Kit (TaKaRa, Kyoto, Japan). All cDNA samples were stored at $-20{ }^{\circ} \mathrm{C}$ for RT-qPCR analysis.

Quantitative real-time PCR (RT-qPCR) was performed with Mastercycler ep realplex (Eppendorf, Germany) using the SYBR green detection protocol. RT-qPCR primers sequences are shown in Table 1, which was according to the design of Wang et al. (2013). The reactions were conducted according to the manufacturer's instructions. Translation elongation factor 2 (TEF2, JQ732180.1) was used as an internal control. Each RNA sample was run in triplicate.

\section{Statistical analysis}

Statistical analysis was conducted using the SAS software package (version 8.0; SAS institute, Cary, NC). Mean separations were compared using Duncan's multiple range tests $(P=0.05)$.

\section{Results and Discussion}

$\mathrm{CI}$ index and $\mathrm{H}_{2} \mathrm{O}_{2}$ concentrations. Peach fruit development CI within 1 to 2 weeks when stored at $2-5{ }^{\circ} \mathrm{C}$, developing internal browning, juicelessness, mealiness, internal reddening, and other imperfections (Crisosto and Labavitch, 2002; Lurie and Crisosto, 2005). These symptoms appear to be related to the accumulation of ROS, particularly $\mathrm{H}_{2} \mathrm{O}_{2}$ (Wang et al., 2009). Internal browning was found in 'Yulu' peach fruit after $21 \mathrm{~d}$ of storage at $5{ }^{\circ} \mathrm{C}$, and the $\mathrm{CI}$ index increased sharply with storage time (Fig. 1A). In contrast, no CI was observed in peach fruit stored at $10{ }^{\circ} \mathrm{C}$ during the $28-\mathrm{d}$ storage period. Throughout the storage period, $\mathrm{H}_{2} \mathrm{O}_{2}$ concentrations in fruit at $10{ }^{\circ} \mathrm{C}$ were significantly lower than those observed in fruit kept at $5{ }^{\circ} \mathrm{C}$ (Fig. 1B).

Concentrations of sucrose and other soluble sugars. As expected for the predominant sugar in postharvest peach fruit, sucrose concentrations were highest, followed by sorbitol, fructose, and glucose (Fig. 2). As shown in Fig. 2A, the sorbitol concentration in peach fruit stored at $10{ }^{\circ} \mathrm{C}$ decreased sharply during storage, whereas the concentration in fruit stored at $5{ }^{\circ} \mathrm{C}$ decreased moderately during the first $21 \mathrm{~d}$ before slightly increasing at the later time point. Fructose and glucose concentrations exhibited a comparable profile over the course of storage (Fig. 2B and C). The concentrations of both reducing sugars generally decreased over time in fruit stored at $10^{\circ} \mathrm{C}$, reaching a minimum at day 21 , before increasing somewhat. While at $5{ }^{\circ} \mathrm{C}$, their concentrations generally increased over time, gradually during the first $14 \mathrm{~d}$ of storage then more rapidly during the latter. The profile for sucrose concentrations during storage differed from that of the other sugars. In fruit stored at $10{ }^{\circ} \mathrm{C}$ sucrose increased, the concentrations becoming significant at day 14 . After day 21, there was a slightly decrease but concentrations remained significantly higher than in fruit immediately after harvest (Fig. 2D). At $5{ }^{\circ} \mathrm{C}$ sucrose decreased continuously, and was significantly lower than concentrations in fruit stored at $10{ }^{\circ} \mathrm{C}$ by $14 \mathrm{~d}$ and beyond.

In our previous study, Wang et al. (2013) found that sucrose in peaches stored at $0{ }^{\circ} \mathrm{C}$ were significantly higher than in fruit stored at $5{ }^{\circ} \mathrm{C}$. Interestingly, in the present study, the 
reduction in sucrose in peach fruit at $10{ }^{\circ} \mathrm{C}$ was significantly slower than at $5{ }^{\circ} \mathrm{C}$. Biochemical reactions are ordinarily expected to proceed more rapidly at higher temperatures, and those unexpected results suggest that sucrose cleavage is induced in peaches at $5{ }^{\circ} \mathrm{C}$. Sucrose is thought to play diverse roles in protecting plants from damage caused by environmental stress. Anchordoguy et al. (1987) demonstrated that sucrose and trehalose were the most effective cryoprotectants. Shalaev and Steponkus (2001) demonstrated that sucrose contributed to the stabilization of liposomes during dehydration. Sucrose may also protect membrane integrity in peach fruit, since sucrose concentration was negatively correlated with electrolyte leakage from the cell membrane ( $r=-0.84$ ) (Wang et al. 2013). Interestingly, in vitro studies have demonstrated that sucrose possesses superior antioxidant capability compared with other sugars (Nishizawa et al., 2008). Sucrose may function at low concentrations as a substrate or signal for stress-induced alterations and can act directly as a protective agent at high concentrations (Uemura and Steponkus, 2003). Sucrose up-regulated ascorbate concentration and the expression of related genes in harvested broccoli florets (Nishikawa et al., 2005).

Abidi et al. (2015) demonstrated that some peach cultivars with high sucrose and glucose concentrations exhibit reduced CI during cold storage; however, Wang et al.
(2013) suggested that only higher concentrations of sucrose contribute to enhanced chilling tolerance in peach fruit. Jiang et al. (2013) also suggested that sucrose is more important than hexose in protecting grape branches from CI at low temperature. Holland et al. (2002) found that only sucrose was involved in heat-induced chilling tolerance of citrus fruit. In the experiment presented here, fruit stored at $5{ }^{\circ} \mathrm{C}$ exhibited severe $\mathrm{CI}$ and had markedly lower concentrations of sucrose than fruit stored at $10{ }^{\circ} \mathrm{C}$ after $14 \mathrm{~d}$. We conclude that sucrose concentrations are related to CI, but there is insufficient evidence to determine whether the change in sucrose concentration causes CI or results from it.

Activities of sucrose-metabolizing enzymes. AI, NI, and SS-cleavage are involved in the decomposition of sucrose, while SS-synthesis and SPS are factors in sucrose biosynthesis (Guo et al., 2002). In fruit stored at $5{ }^{\circ} \mathrm{C}$, activities for all five enzymes generally increased over the course of $28 \mathrm{~d}$ (Fig. 3A-E), although the most dramatic change was observed for AI activity, reaching 3.8-fold higher at day 28 relative to level at day 0 (maximum relative changes for NI, SS-cleavage, SSsynthesis, and SPS activities were 2.4-, 2.0-, 2.0-, 2.5-fold, respectively). Net cleavage activity in fruit at $5{ }^{\circ} \mathrm{C}$ was positive and increased with time (Fig. 3F), which was consistent with the dramatic decline in sucrose concentration and the formation of reducing sugars (Fig. 2).

Table 1. Primer sequences used for real-time polymerase chain reaction.

\begin{tabular}{lll}
\hline Gene & \multicolumn{1}{c}{ Forward primer sequence $\left(5^{\prime}-3^{\prime}\right)$} & \multicolumn{1}{c}{ Reverse primer sequence $\left(5^{\prime}-3^{\prime}\right)$} \\
\hline AI & TCATACGCCCATACCACCAG & CGAAATCGGAATCGAATAGC \\
NI/1 & TGCTCTGGAGTATGAAGAATGG & ATCCACTGCCTTTTGTGCTAAC \\
NI/2 & CTATGACACCAAAAGGGGTAGG & GCTTTCTTCTTGGGTTAGCACT \\
NI/3 & GGGTACTCCAAAGCAAAATGAC & TATGACCAAGGGGTATTCTTCG \\
NI/ 4 & ATGGTATGGCGATTCTTTCATC & AGACCCTCAGTTGTGTAGCTC \\
SS & ATGAGGAGAAGGCTGAGATGAAG & CAAGTAGCGAATGTTGGAAGTC \\
SPS $/ 1$ & TTGAGGCTACAGGAAAGGAAAG & GGACGCTCCTCTGAATGAATAG \\
SPS/2 & CTTCCCTTTGTGGTGGATTTAG & GAGTTCCTTAACAGGGGGAATC \\
TEF2 & TGAAGGAGAGGGAAGGTGAAAG & GGTGTGACGATGAAGAGTGATG \\
\hline
\end{tabular}

In contrast, at $10^{\circ} \mathrm{C}, \mathrm{AI}$ and SS-cleavage activities decreased after $7 \mathrm{~d}$ of storage following an initial increase. SS-synthesis activity also showed an initial increase but declined or leveled off afterward. NI activity maintained a declining trend throughout storage. SPS activity followed a distinctly different pattern, increasing until day 14 and declining thereafter. The combination of increased synthesis activity and decreased cleavage activity at later storage times explained the increase in sucrose concentration at $10{ }^{\circ} \mathrm{C}$ and the decrease in reducing sugars. Starch concentration in harvested peach fruit is very low (Bianco and Rieger, 2002), and in our study ranged from 0.8 to $1.7 \mathrm{mg}$ glucose per g FW (date not shown). Under starch-limiting conditions, starch is unlikely to contribute to sucrose accumulation, but reducing sugars in fruit stored at $10{ }^{\circ} \mathrm{C}$ are potential sources for the formation of sucrose.

Compared with fruit stored at $10{ }^{\circ} \mathrm{C}$, activities of AI, NI, SS, and SPS at $5{ }^{\circ} \mathrm{C}$ were higher after day 14 of storage. The net sucrose cleavage activity at $10{ }^{\circ} \mathrm{C}$ was distinctly lower than that observed at $5{ }^{\circ} \mathrm{C}$ in fruit after day 7 . Various reports suggest that plants respond to abiotic stress by increasing the activity of sucrose metabolism enzymes. In banana fruit treated with ethylene, AI, NI, SS, and SPS activities were enhanced dramatically relative to untreated fruit (Li et al., 2011). In cucumber leaves, salicylic acid promoted SS and SPS activities (Dong et al., 2011). In addition, heat treatment also elevated the activities of AI, NI, SS, and SPS in loquat fruit (Shao et al., 2013). Zhang et al. (2010) examined proteome patterns in peach fruit stored at 0 and $5{ }^{\circ} \mathrm{C}$ and demonstrated that the relevant enzymes involved in sugar metabolism and energy pathways decreased in fruit stored at $0{ }^{\circ} \mathrm{C}$. In this study, enzymes involved in sucrose metabolism were induced under conditions of chilling stress and were found at higher levels than in fruit at nonchilling temperatures.
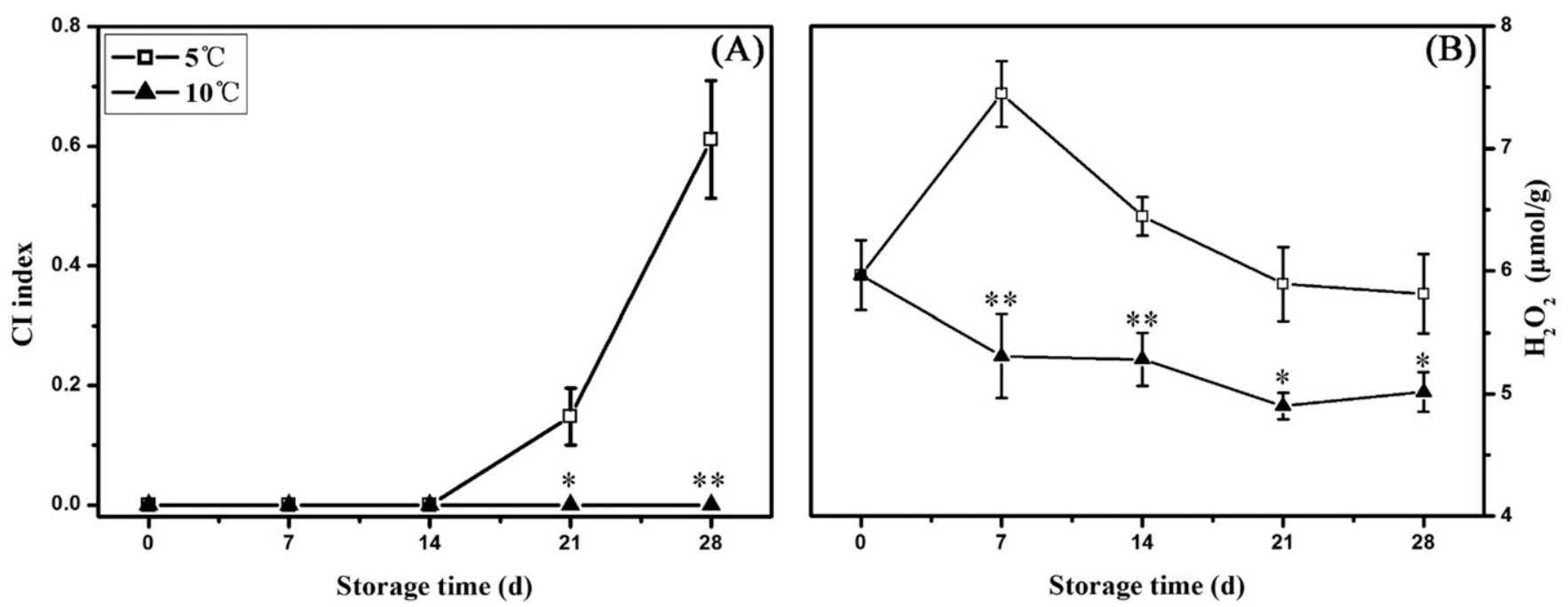

Fig. 1. CI index (A) and $\mathrm{H}_{2} \mathrm{O}_{2}$ concentration $(\mathbf{B})$ in peach fruit during storage at 5 and $10{ }^{\circ} \mathrm{C}$. Vertical bars represent $\mathrm{SE}$ of the means. $* P<0.05 ; * * P<0.01$ based on Duncan's multiple range test between 5 and $10{ }^{\circ} \mathrm{C}$ at each time point. 

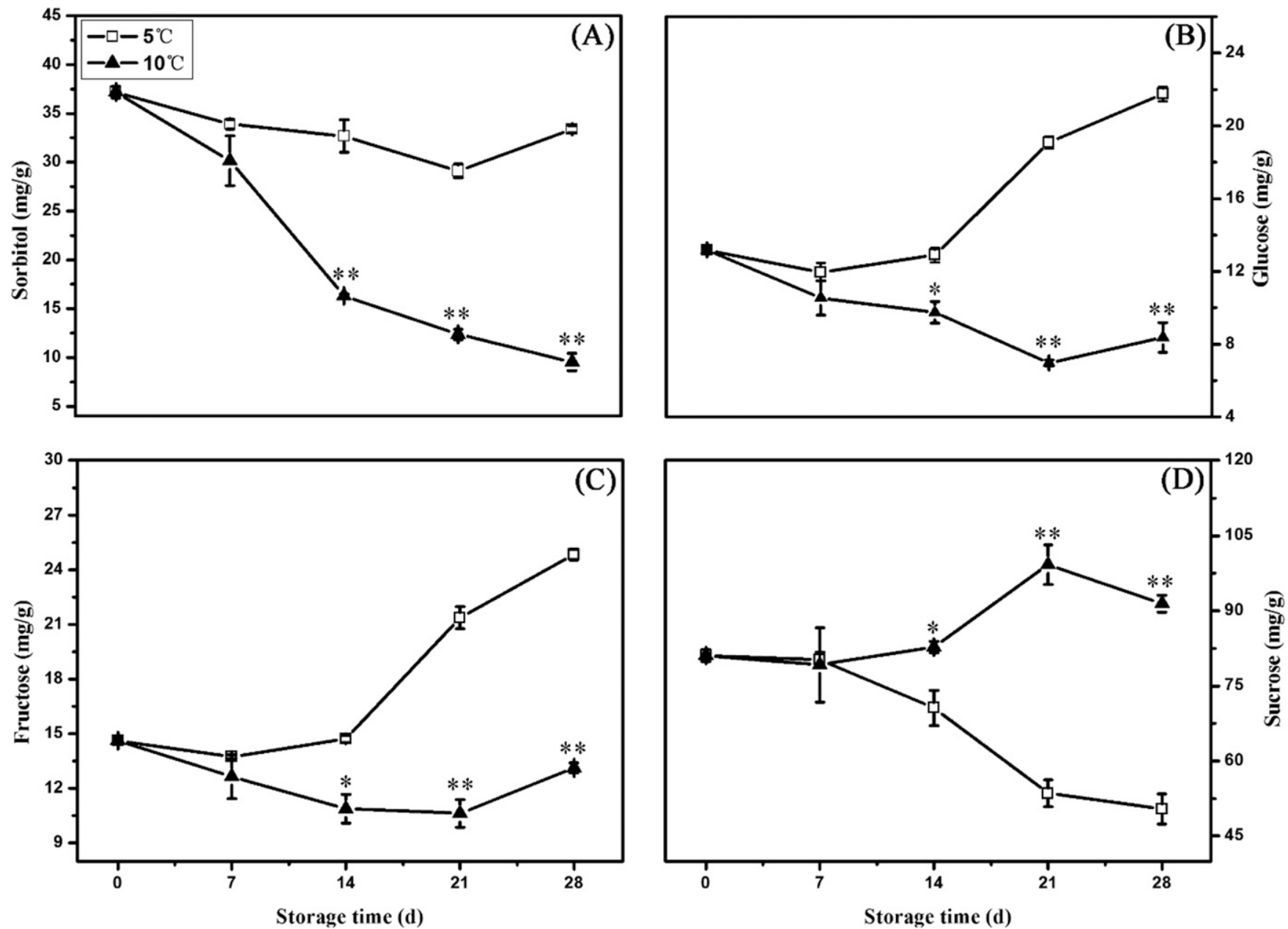

Fig. 2. Sorbitol (A), glucose (B), fructose (C), and sucrose (D) concentrations in peach fruit during storage at 5 and $10{ }^{\circ} \mathrm{C}$. Vertical bars represent SE of the means. ${ }^{*} P<0.05 ;{ }^{*} P<0.01$ based on Duncan's multiple range test between 5 and $10{ }^{\circ} \mathrm{C}$ at each time point.
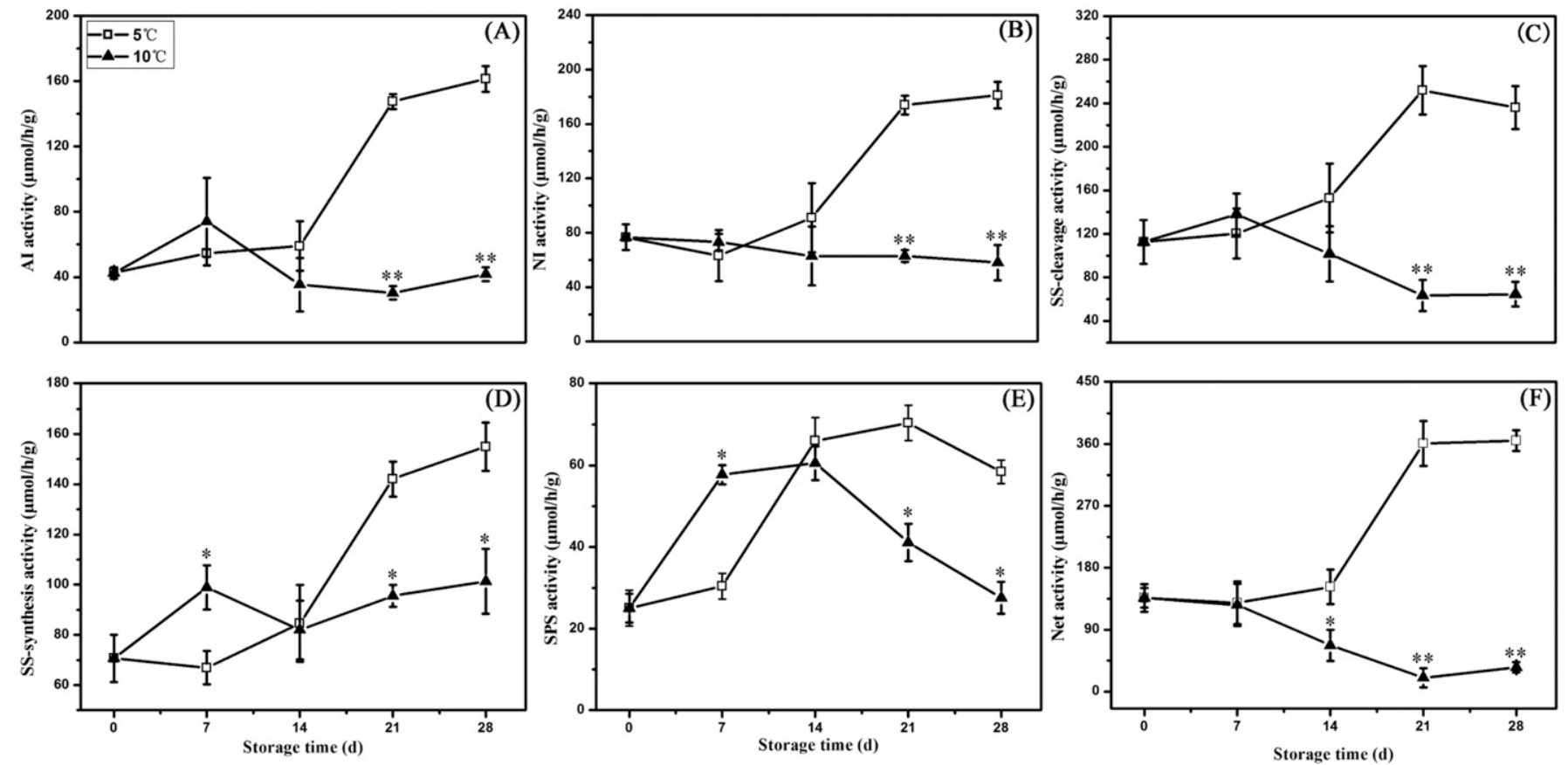

Fig. 3. AI (A), NI (B), SS-cleavage (C), SS-synthesis (D), SPS (E) activities, and net activity (F) in peach fruit stored at 5 and $10{ }^{\circ} \mathrm{C}$ for $28 \mathrm{~d}$. Vertical bars represent SE of the means. ${ }^{*} P<0.05 ; * * P<0.01$ based on Duncan's multiple range test between 5 and $10{ }^{\circ} \mathrm{C}$ at each time point. 
Transcription levels of genes involved in sucrose metabolism. In fruit stored at $5{ }^{\circ} \mathrm{C}$, transcript levels of AI, NI/2, NI/3, SS, SPS/1, and SPS/2 increased dramatically during the first $21 \mathrm{~d}$ and then declined (Fig. 4A, C, D, F-H). The relative change in AI transcript levels was by far the greatest, reaching nearly 3000 -fold at day 21 relative to levels at day 0 (maximum relative levels for NI, SS, and SPS were 6.2-, 6.1-, and 5.4-fold, respectively). $\mathrm{NI} / 1$ transcript levels rose abruptly at day 21 and then declined (Fig. 4B). In contrast, NI/4 transcript levels decreased with storage time (Fig. 4E). Although transcript levels for SPS/1 and SPS/2 increased during storage at $5{ }^{\circ} \mathrm{C}$ (Fig. 4G and $\mathrm{H}$ ), the net sucrose degradation we observed can be attributed to the substantial increase in AI transcript levels.
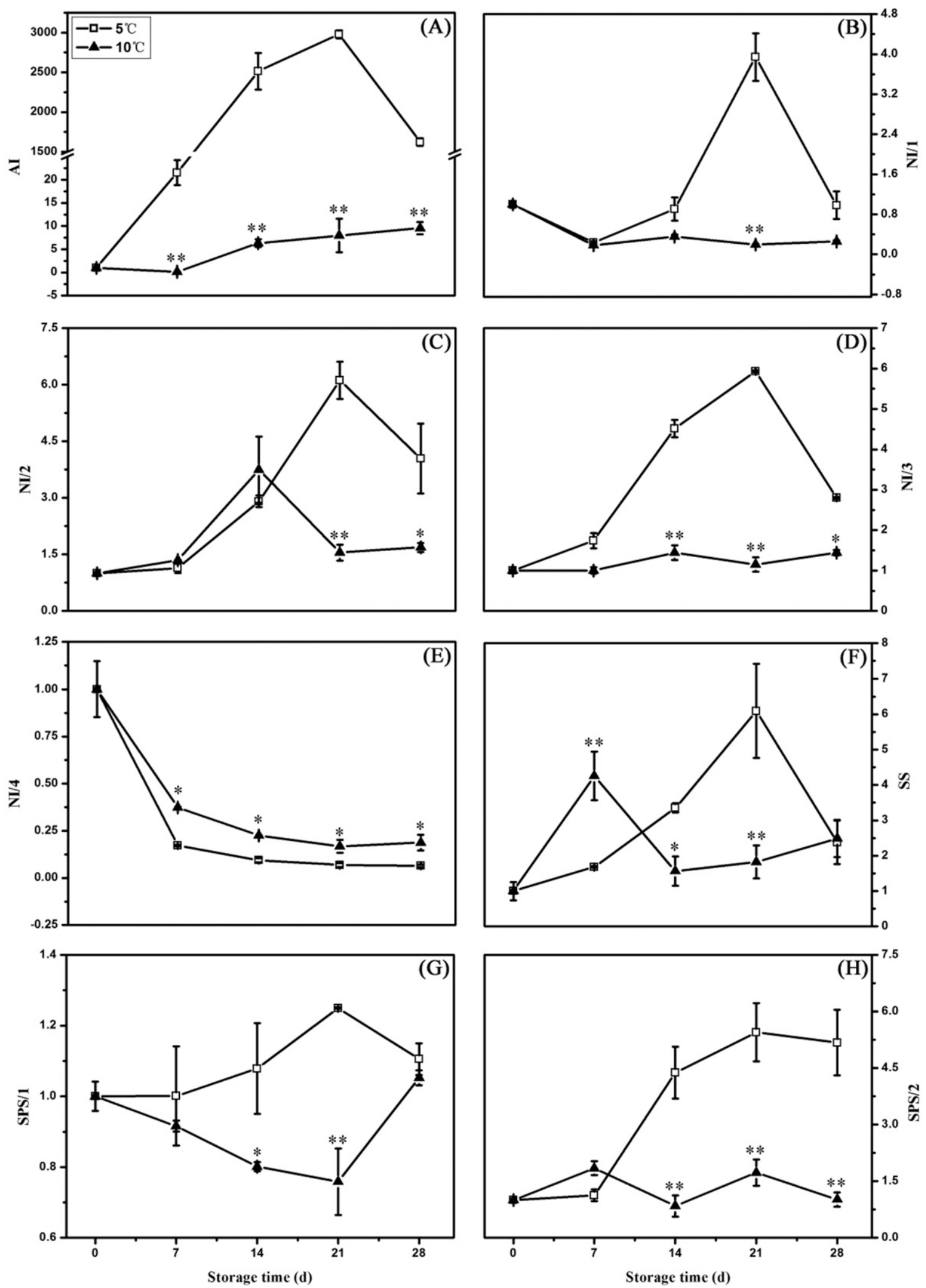

Fig. 4. Relative transcription levels of genes encoding enzymes involved in sucrose metabolism in peach fruit stored at 5 and $10{ }^{\circ} \mathrm{C}$. (A) AI; (B-E) NI/1-4; (F) SS; (G-H) SPS/1-2. Vertical bars represent SE of the means. ${ }^{*} P<0.05$; ${ }^{*} P<0.01$ based on Duncan's multiple range test between 5 and $10{ }^{\circ} \mathrm{C}$ at each time point. 
In fruit stored at $10{ }^{\circ} \mathrm{C}$, AI and $\mathrm{NI} / 3$ transcript levels increased slightly with storage time (Fig. 4A and D). NI/1 and NI/4 gene expression both exhibited steady decreases (Fig. 4B and E). NI/2 gene expression increased first and then decreased, with a peak value at day 14 (Fig. 4C). The level for SS increased first before decreasing, peaking at day 7 (Fig. 4F). SPS/1 transcripts declined continuously over $21 \mathrm{~d}$, and then rose sharply (Fig. 4G). Finally, SPS/2 transcripts exhibited irregular, slight changes (Fig. 4H). During 14 to $21 \mathrm{~d}$ of cold storage at $10{ }^{\circ} \mathrm{C}$, a significant increase in sucrose concentration occurred (Fig. 2A), probably due to the upregulation of SPS/2 and downregulation of sucrose cleavage enzymes. The upregulation of AI and SS and the downregulation of SPS $/ 2$ probably accounted for the large decline in sucrose levels observed by the end of the storage period.

Comparing gene expression at the two temperatures, fruit stored at $5{ }^{\circ} \mathrm{C}$ had markedly higher transcript levels than fruit stored at $10{ }^{\circ} \mathrm{C}$ for $\mathrm{AI}, \mathrm{NI} / 1-3, \mathrm{SS}$, and SPS/1-2 (NI/4 was the exception). Other researchers have suggested that chilling stress not only stimulates the activities of sucrose metabolism enzymes but also influences their transcription levels. Itai and Tanahashi (2008) suggested that cold treatment $\left(5^{\circ} \mathrm{C}\right)$ in Japanese pear leads to sucrose degradation and an accumulation of hexoses due to the upregulation of AI transcription and the downregulation of SPS1 transcription. Wang et al. (2013) suggested that higher transcript levels for $\mathrm{AI}, \mathrm{NI} / 2$, and $\mathrm{SS}$, higher activities of $\mathrm{AI}$ and NI, and lower transcript levels for SPS/1 may be responsible for sucrose loss in peaches stored at $5{ }^{\circ} \mathrm{C}$ relative to controls at $0{ }^{\circ} \mathrm{C}$. In the results reported here, variations in sucrose concentration in fruit stored at $5{ }^{\circ} \mathrm{C}$ vs. $10{ }^{\circ} \mathrm{C}$ were most likely due to the strikingly higher levels of AI transcripts and activity. AI has been reported to play a regulatory role in response to environmental stress. During pathogen-induced biotic stress, increasing invertase activity couples the carbohydrate sink to the plant defense response (Bonfig et al., 2010). In addition, under abiotic stress conditions such as salinity, extracellular invertase was upregulated to supply carbohydrates to sink organs (Roitsch et al., 2003). AI activity was strongly enhanced in mature maize leaves when subjected to water stress (Trouverie et al., 2003). Moreover, low temperature strongly induced AI (StvacINV1) gene expression in potato tubers (Liu et al., 2011). Invertase has also been identified as a conserved sugar signaling factor (Keunen et al., 2013). We therefore suggest that the sharp increase in AI gene expression observed in peach fruit at $5{ }^{\circ} \mathrm{C}$ may function in part as a signal of chilling stress.

\section{Conclusions}

This study focuses on the response of peach fruit to storage at $10{ }^{\circ} \mathrm{C}$. Although the results have practical implications, they also provide a detailed look at differences in sucrose metabolism under conditions of chilling stress or nonstressful temperatures. Biochemical reactions typically proceed more rapidly as temperature increases. However, our data show that enzyme activities and the expression of genes related to sucrose metabolism were induced in peach fruits under chilling stress, and enhanced concentrations of sucrose cleavage caused a sharp decline in sucrose at $5{ }^{\circ} \mathrm{C}$. In contrast, increased synthesis and decreased cleavage activities were responsible for increased sucrose concentrations in fruit stored at $10{ }^{\circ} \mathrm{C}$. In our earlier study, comparing storage at 0 and $5{ }^{\circ} \mathrm{C}$ (Wang et al., 2013), and in our present study comparing storage at 5 and $10{ }^{\circ} \mathrm{C}$, increased sucrose concentrations were associated with higher chilling tolerance in postharvest peaches. However, it is not yet clear whether changes in sucrose concentrations cause $\mathrm{CI}$ or result from it, and additional experiments will be required to distinguish these models.

\section{Literature Cited}

Abidi, W., C.M. Cantin, S. Jimenez, R. Gimenez, M.A. Moreno, and Y. Gogorcena. 2015. Influence of antioxidant compounds, total sugars and genetic background on the chilling injury susceptibility of a non-melting peach (Prunus persica (L.) Batsch) progeny. J. Sci. Food Agr. 95:351-358.

Anchordoguy, T.J., A.S. Rudolph, J.F. Carpenter, and J.H. Crowe. 1987. Modes of interaction of cryoprotectants with membrane phospholipids during freezing. Cryobiology 24:324-331.

Aubert, C., P. Bony, G. Chalot, P. Landry, and S. Lurol. 2014. Effects of storage temperature, storage duration, and subsequent ripening on the physicochemical characteristics, volatile compounds, and phytochemicals of western red nectarine (Prunus persica L. Batsch). J. Agr. Food Chem. 62:4707-4724.

Bianco, R.L. and M. Rieger. 2002. Partitioning of sorbitol and sucrose catabolism within peach fruit. J. Amer. Soc. Hort. Sci. 127:115-121.

Bonfig, K.B., A. Gabler, U.K. Simon, N. LuschinEbengreuth, M. Hatz, S. Berger, N. Muhammad, J. Zeier, A.K. Sinha, and T. Roitsch. 2010. Post-translational derepression of invertase activity in source leaves via down-regulation of invertase inhibitor expression is part of the plant defense response. Mol. Plant 3:10371048.

Borsani, J., C.O. Budde, L. Porrini, M.A. Lauxmann, V.A. Lombardo, R. Murray, C.S. Andreo, M.F. Drincovich, and M.V. Lara. 2009. Carbon metabolism of peach fruit after harvest: Changes in enzymes involved in organic acid and sugar level modifications. J. Expt. Bot. 60:18231837.

Cao, S., Z. Yang, and Y. Zheng. 2013. Sugar metabolism in relation to chilling tolerance of loquat fruit. Food Chem. 136:139-143.

Crisosto, C.H. and J.M. Labavitch. 2002. Developing a quantitative method to evaluate peach (Prunus persica) flesh mealiness. Postharvest Biol. Technol. 25:151-158.

Dong, C.J., X.L. Wang, and Q.M. Shang. 2011. Salicylic acid regulates sugar metabolism that confers tolerance to salinity stress in cucumber seedlings. Sci. Hort. 129:629-636.

Guo, J., W.A. Jermyn, and M.H. Turnbull. 2002. Carbon assimilation, partitioning and export in mature cladophylls of two asparagus (Asparagus officinalis) cultivars with contrasting yield. Physiol. Plant. 115:362-369.

Hoffmann, C.M. 2010. Sucrose accumulation in sugar beet under drought stress. J. Agron. Crop Sci. 196:243-252.

Holland, N., H.C. Menezes, and M.T. Lafuente. 2002. Carbohydrates as related to the heatinduced chilling tolerance and respiratory rate of 'Fortune' mandarin fruit harvested at different maturity stages. Postharvest Biol. Technol. 25:181-191.

Itai, A. and T. Tanahashi. 2008. Inhibition of sucrose loss during cold storage in Japanese pear (Pyrus pyrifolia Nakai) by 1-MCP. Postharvest Biol. Technol. 48:355-363.

Jiang, H.Y., W. Li, B.J. He, Y.H. Gao, and J.X. Lu. 2013. Sucrose metabolism in grape (Vitis vinifera $\mathrm{L}$.) branches under low temperature during overwintering covered with soil. Plant Growth Regulat. 72:229-238.

Jin, P., H. Shang, J. Chen, H. Zhu, Y. Zhao, and Y. Zheng. 2011. Effect of 1-methylcyclopropene on chilling injury and quality of peach fruit during cold storage. J. Food Sci. 76:485-491.

Keunen, E., D. Peshev, J. Vangronsveld, W. Van den Ende, and A. Cuypers. 2013. Plant sugars are crucial players in the oxidative challenge during abiotic stress: Extending the traditional concept. Plant Cell Environ. 36:1242-1255.

Lara, M.V., C.O. Budde, L. Porrini, J. Borsani, R. Murray, C.S. Andreo, and M.F. Drincovich. 2011. Peach (Prunus persica) fruit response to anoxia: Reversible ripening delay and biochemical changes. Plant Cell Physiol. 52:392403.

Li, W., Y. Shao, W. Chen, and W. Jia. 2011. The effects of harvest maturity on storage quality and sucrose-metabolizing enzymes during $\mathrm{Ba}-$ nana ripening. Food Bioprocess Tech. 4:12731280.

Liu, X., C. Zhang, Y. Ou, Y. Lin, B. Song, C. Xie, J. Liu, and X.Q. Li. 2011. Systematic analysis of potato acid invertase genes reveals that a coldresponsive member, StvacINV1, regulates coldinduced sweetening of tubers. Mol. Genet. Genomics 286:109-118.

Lukatkin, A.S., A. Brazaityte, C. Bobinas, and P. Duchovskis. 2012. Chilling injury in chillingsensitive plants: A review. ZemdirbysteAgriculture 99:111-124.

Lurie, S. and C.H. Crisosto. 2005. Chilling injury in peach and nectarine. Postharvest Biol. Technol. 37:195-208.

Meisel, L., B. Fonseca, S. González, R. BaezaYates, V. Cambiazo, R. Campos, M. González, A. Orellana, J. Retamales, and H. Silva. 2005. A rapid and efficient method for purifying high quality total RNA from peaches (Prunus persica) for functional genomics analyses. Biol. Res. 38:83-88.

Meng, X., J. Han, Q. Wang, and S. Tian. 2009. Changes in physiology and quality of peach fruits treated by methyl jasmonate under low temperature stress. Food Chem. 114:1028-1035.

Miller, G.L. 1959. Use of dinitrosalicylic acid reagent for determination of reducing sugar. Anal. Chem. 31:426-428.

Nishikawa, F., M. Kato, H. Hyodo, Y. Ikoma, M. Sugiura, and M. Yano. 2005. Effect of sucrose on ascorbate level and expression of genes involved in the ascorbate biosynthesis and recycling pathway in harvested broccoli florets. J. Expt. Bot. 56:65-72.

Nishizawa, A., Y. Yabuta, and S. Shigeoka. 2008. Galactinol and raffinose constitute a novel function to protect plants from oxidative damage. Plant Physiol. 147:1251-1263. 
Roitsch, T., M. Balibrea, M. Hofmann, R. Proels, and A. Sinha. 2003. Extracellular invertase: Key metabolic enzyme and PR protein. J. Expt. Bot. 54:513-524.

Shalaev, E.Y. and P. Steponkus. 2001. Phase behavior and glass transition of 1,2- dioleoylphosphatidylethanolamine (DOPE) dehydrated in the presence of sucrose. BBA-Biomembranes 1514:100-116.

Shao, X., Y. Zhu, S. Cao, H. Wang, and Y. Song. 2013. Soluble sugar content and metabolism as related to the heat-induced chilling tolerance of loquat fruit during cold storage. Food Bioprocess Tech. 6:3490-3498.

Solomakhin, A.A. and M.M. Blanke. 2010. Mechanical flower thinning improves the fruit quality of apples. J. Sci. Food Agr. 90:735-741.

Trouverie, J., C. Thévenot, J.P. Rocher, B. Sotta, and J.L. Prioul. 2003. The role of abscisic acid in the response of a specific vacuolar invertase to water stress in the adult maize leaf. J. Expt. Bot. 54:2177-2186.
Uemura, M. and P.L. Steponkus. 2003. Modification of the intracellular sugar content alters the incidence of freeze-induced membrane lesions of protoplasts isolated from Arabidopsis thaliana leaves. Plant Cell Environ. 26:10831096.

Uemura, M., G. Warren, and P.L. Steponkus. 2003. Freezing sensitivity in the sfr4 mutant of Arabidopsis is due to low sugar content and is manifested by loss of osmotic responsiveness Plant Physiol. 131:1800-1807.

van Handel, E. 1968. Direct microdetermination of sucrose. Anal. Biochem. 22:280-283.

Wang, B., J. Wang, X. Feng, L. Lin, Y. Zhao, and W. Jiang. 2009. Effects of 1-MCP and exogenous ethylene on fruit ripening and antioxidants in stored mango. Plant Growth Regulat. 57:185-192.

Wang, K., X. Shao, Y. Gong, Y. Zhu, H. Wang, X. Zhang, D. Yu, F. Yu, Z. Qiu, and H. Lu. 2013. The metabolism of soluble carbohydrates related to chilling injury in peach fruit exposed to cold stress. Postharvest Biol. Technol. 86:53-61.

Wang, K., X. Shao, Y. Gong, F. Xu, and H. Wang. 2014. Effects of postharvest hot air treatment on gene expression associated with ascorbic acid metabolism in peach fruit. Plant Mol. Biol. Rpt. 32:881-887.

Yang, A., S. Cao, Z. Yang, Y. Cai, and Y. Zheng. 2011. $\gamma$-Aminobutyric acid treatment reduces chilling injury and activates the defence response of peach fruit. Food Chem. 129:16191622.

Zhang, C., Z. Ding, X. Xu, Q. Wang, G. Qin, and S. Tian. 2010. Crucial roles of membrane stability and its related proteins in the tolerance of peach fruit to chilling injury. Amino Acids 39:181-194.

Zhao, F., L. Jing, F. Yan, D. Lu, G. Wang, and W. Lu. 2013. Effect of heat stress during grain filling on sugar accumulation and enzyme activity associated with sucrose metabolism in sweet corn. Acta Agron. Sin. 39:1644-1651. 